\title{
TERMOTERAPIA VIA CALOR SECO NO TRATAMENTO DE SEMENTES DE TOMATE: EFICIÊNCIA NA ERRADICAÇÃO DE Xanthomonas campestris pv. vesicatoria E EFEITOS SOBRE A SEMENTE
}

\author{
ÂNGELO M. S. SILVA ${ }^{1}$, MARGARIDA G. F. CARMO ${ }^{2}$, FÁBIO L. OLIVARES ${ }^{3} \&$ ARISON J. PEREIRA ${ }^{4}$ \\ ${ }^{1}$ Curso de Pós Graduação em Fitotecnia, ${ }^{2,4}$ Departamento de Fitotecnia, Universidade Federal Rural do \\ Rio de Janeiro, CEP 23.890-000, Seropédica, RJ, e-mail: gorete@ufrrj.br; ${ }^{3}$ Laboratório de Biologia Celular e \\ Tecidual, CBB/UENF, Campos dos Goytacazes, RJ
}

(Aceito para publicação em 26/09/2002)

\begin{abstract}
Autor para correspondência: Margarida Goréte F. do Carmo
\end{abstract}
SILVA, A.M.S., CARMO, M.G.F., OLIVARES, F.L. \& PEREIRA, A.J. Termoterapia via calor seco no tratamento de sementes de tomate: eficiência na erradicação de Xanthomonas campestris pv. vesicatoria e efeitos sobre a semente. Fitopatologia Brasileira 27:586-593. 2002.

\section{RESUMO}

Sementes infetadas constituem fonte primária de inóculo para epidemias da mancha bacteriana do tomate (Lycopersicon esculentum) que sob condições favoráveis podem resultar em rápido desenvolvimento da doença e severas perdas. $\mathrm{O}$ presente trabalho objetivou avaliar a eficiência do tratamento térmico a 70 ${ }^{\circ} \mathrm{C}$ por $96 \mathrm{~h}$ na erradicação de Xanthomonas campestris pv. vesicatoria de sementes de tomate e seu efeito sobre a qualidade fisiológica e estrutura das sementes, por meio de microscopia eletrônica de varredura (MEV). Realizaram-se dois ensaios, e utilizando-se sementes inoculadas pelo método a vácuo com o isolado ENA 4463 a $10^{7} \mathrm{ufc} / \mathrm{ml}$ em $\mathrm{NaCl}(0,85 \%)$. No primeiro ensaio compararam-se quatro tratamentos: sementes inoculadas (1), sementes inoculadas e tratadas a $70{ }^{\circ} \mathrm{C} / 96 \mathrm{~h}$ em estufa com circulação forçada de ar (2), sementes não inoculadas e não tratadas
(3) e sementes não inoculadas e tratadas $\left(70{ }^{\circ} \mathrm{C} / 96 \mathrm{~h}\right)$ (4). No segundo ensaio, apenas os tratamentos (1), (2) e (3) foram comparados. As amostras foram avaliadas quanto à qualidade fisiológica e recuperação da fitobactéria por meio de extração a vácuo seguido de riscagem em meios semi-seletivos, além de observações em MEV. Constatou-se eficiência de 100\% e 99,96\% na erradicação da bactéria no primeiro e segundo ensaio, respectivamente. Não houve nenhum efeito do tratamento térmico sobre a germinação. Observações ao MEV, revelaram alterações na estrutura superficial das sementes, com remoção, quebra e fusão de tricomas, além de danos à integridade das células bacterianas associadas à superfície do tegumento.

Palavras-chave adicionais: Lycopersicon esculentum, patologia de sementes, estrutura da semente, mancha-bacteriana.

\section{ABSTRACT \\ Dry heat therapy treatment of tomato seeds: eradication efficiency of Xanthomonas campestris pv. vesicatoria and effects on seed structure}

Infected seed is the primary source of tomato (Lycopersicon esculentum) bacterial spot causing a rapid development of the disease with severe yield losses under favorable environmental conditions. The present work was undertaken to evaluate the effect of heat treatment $\left(70{ }^{\circ} \mathrm{C}\right.$ for $\left.96 \mathrm{~h}\right)$ on germination and seed structure, as well as to determine the efficiency of heat therapy to prevent bacterial growth and disease establishment. Two experiments were carried out using tomato seeds inoculated by vacuum with Xanthomonas campestris pv. vesicatoria strain ENA 4463 adjusted to $10^{7}$ cells. $\mathrm{ml}^{-1}$ followed by air-drying. In the first assay, four treatments were designed as follows: (1) inoculated seeds; (2) inoculation followed by heat treatment $\left(70{ }^{\circ} \mathrm{C} / 96 \mathrm{~h}\right)$; and two controls, uninoculated seeds without (3) and with (4) heat treatment. In the second assay, three treatments:
(1), (2) and (3) were compared. Samples from different treatments were evaluated for the physiological status of the seeds and presence of the bacteria. The latter was tested by recovering the bacteria by vacuum extraction, isolation in semi-selective medium and visualizations though scanning electron microscopy (SEM). The efficiency of the heat treatment as a method to control the disease ranged from 99,96 to $100 \%$ for the second and first assay, respectively. Furthermore, there was no significant effect of the heat on seed germination. However, under SEM, heat treated seed showed some superficial structural changes, characterized by a greater number of broken trichomes, and a deposition of trichomes randomly or organized in plates over the seed surface and morphological changes in the bacterial cell shape.

\section{INTRODUÇÃO}

O tomate (Lycopersicon esculentum Mill.) é a hortaliça com maior volume de comercialização no Brasil (3,0 milhões de t/ano) (IBGE, 2000). A cultura, porém, está sujeita a várias fitobacterioses e dentre estas, a mancha-bacteriana causada por Xanthomonas campestris pv. vesicatoria (Doidge) Dye. A doença é altamente destrutiva podendo afetar toda a parte aérea do tomateiro, levando a perdas na quantidade e qualidade dos frutos (Robbs, 1985; Lopes \& Santos, 1994). Sementes contaminadas representam a principal fonte de inóculo primário e mesmo em baixas proporções, podem 
Termoterapia via calor seco no tratamento de sementes de tomate...

resultar em severas epidemias da doença no viveiro e no campo, com conseqüentes perdas na produção, principalmente sob ambiente com umidade elevada e temperaturas moderadas (Romeiro, 1988; Schaad, 1988; Carmo et al., 1996). Como a maioria das bacterioses, a mancha-bacteriana do tomate também é de difícil controle no campo. Esta dificuldade é decorrente, entre outros fatores, da baixa eficiência dos antibióticos (Stall \& Thayer, 1962; Jones et al., 1991), bem como da ocorrência de estirpes resistentes a produtos a base de cobre (Marco \& Stall, 1983; Aguiar et al., 2000) e da inexistência de cultivares comerciais resistentes.

Desse modo, medidas de caráter preventivo, como o uso de sementes sadias ou submetidas a tratamentos eficientes associado a práticas como rotação com gramíneas e plantio distante de lavouras mais velhas, além do manejo adequado de irrigação, são hoje as mais adequadas ao seu controle e, quando necessário, complementadas com pulverizações com cúpricos (Lopes e Santos, 1994).

Entre os métodos de tratamento de sementes descritos na literatura, a termoterapia é uma das mais citadas para erradicação de fitobactérias localizadas interna ou externamente nas sementes (Kimura, 1991; Zambolim, et al., 1997). Por outro lado, pode muitas vezes causar danos à qualidade fisiológica das sementes como, retardamento ou redução da germinação e do vigor (Menten, 1995). Além disso, a sua eficiência depende, em grande parte, do tipo e localização do patógeno alvo, do vigor da semente e da sensibilidade da semente a temperaturas elevadas (Menten, 1995).

A termoterapia pode ser aplicada via calor úmido (água quente ou vapor) ou calor seco. Este último apresenta menor capacidade térmica ou troca de calor que a via úmida, requerendo, portanto, maior tempo de exposição. Entretanto, é mais simples e mais acessível, além de causar menos danos às sementes, já que não há o rompimento do tegumento e/ou extravasamento de substâncias das sementes, comum na embebição em água quente e vapor arejado (Menten, 1995).

Os trabalhos com a utilização da termoterapia via calor seco para a erradicação de fitobactérias em sementes relatam resultados variados quanto à eficiência. Exceto sementes de algumas leguminosas, que são muito sensíveis ao calor, na maioria das demais espécies, o tratamento das sementes por meio de calor seco reduz a infecção das sementes e a incidência de doença com pequena redução na germinação. A faixa de temperatura e os períodos de exposição aplicados às sementes variam de 50 a $85^{\circ} \mathrm{C}$ por um a 11 dias, conforme a espécie hospedeira e a sua sensibilidade ao calor. A sensibilidade das células bacterianas ao calor, que pode variar com a idade da cultura ou das células bacterianas, e até a própria origem geográfica do isolado, também devem ser considerados (Grondeau \& Samson, 1994). Azevedo et al. (1991) relatam controle de $X$. campestris pv. vesicatoria em sementes de pimentão (Capsicum annuum L.) por meio de calor seco, em estufa de circulação forçada de ar. Constataram que a combinação temperatura $\mathrm{x}$ tempo de exposição mais eficiente para erradicação da bactéria nas sementes foi de $80^{\circ} \mathrm{C}$ por 96 $\mathrm{h}$, que resultou, no entanto, em morte das sementes. Por outro lado, temperatura de $70{ }^{\circ} \mathrm{C}$ por $96 \mathrm{~h}$ não interferiu na germinação e apresentou eficiência de 99,99\%.

No entanto, as combinações tempo de exposição x temperatura e forma de aplicação (via seco ou via úmido) relatadas em trabalhos pioneiros para erradicação de bactérias fitopatogênicas em sementes necessitam ser avaliados utilizando-se condições mais precisas de controles de temperatura, bem como métodos mais eficientes de detecção do patógeno nas sementes para determinação de sua eficiência e avaliação dos danos causados à semente (Kimura, 1991).

Dessa forma, o objetivo do presente trabalho foi avaliar a eficiência do tratamento térmico via calor seco na erradicação de $X$. campestris pv. vesicatoria em sementes de tomate, e seu efeito sobre a qualidade fisiológica das sementes e sobre a estrutura das sementes por meio da microscopia eletrônica de varredura (MEV).

\section{MATERIAL E MÉTODOS}

Foram realizados dois ensaios, um no Departamento de Entomologia e Fitopatologia e outro no Departamento de Fitotecnia da UFRRJ, no período de junho de 1999 a junho de 2000 .

\section{Experimento I}

No primeiro ensaio, utilizaram-se sementes comerciais de tomate da cultivar Santa Clara e o isolado ENA 4463 da bactéria. Foram comparados quatro tratamentos: 1) sementes inoculadas a vácuo; 2) sementes inoculadas a vácuo e submetidas ao tratamento térmico $70^{\circ} \mathrm{C}$ por $96 \mathrm{~h}, 3$ ) sementes não inoculadas e tratadas a $70{ }^{\circ} \mathrm{C}$ por $96 \mathrm{~h}$ e 4) testemunha, sementes não inoculadas e não tratadas.

\section{Inoculação das sementes}

Para inoculação das sementes empregou-se a metodologia descrita por Bashan \& Assouline (1983). Utilizando-se suspensão bacteriana em solução salina $(\mathrm{NaCl} 0,85 \%$ p/v), contendo $10^{7} \mathrm{ufc} / \mathrm{ml}$, obtidos a partir de culturas puras de $X$. campestris pv. vesicatoria com $36 \mathrm{~h}$ de crescimento em meio DYGS a $28 \pm 2{ }^{\circ} \mathrm{C}$ (Rodrigues Neto et al., 1986). Após a inoculação, as sementes foram mantidas em câmara de fluxo laminar por $24 \mathrm{~h}$ para uma pré-secagem, seguida de secagem por cinco dias em câmara aquecida por lâmpadas incandescente (40 Watts). Após a secagem, estas foram acondicionadas em envelopes de papel e submetidas ao tratamento térmico. As amostras referentes aos tratamentos 1 e 4, não tratadas, foram armazenadas em geladeira até montagem dos testes.

\section{Tratamento térmico}

$\mathrm{O}$ tratamento térmico foi feito conforme Azevedo et al. (1991). Para tanto, os envelopes contendo as amostras a serem tratadas foram dispostos em estufa com circulação forçada de ar, previamente regulada para a temperatura de $70 \pm 2{ }^{\circ} \mathrm{C}$, onde permaneceram por $96 \mathrm{~h}$. Depois de retirados, foram novamente armazenados em geladeira. Amostras com os respectivos tratamentos foram submetidos a três diferentes 
avaliações: 1) qualidade fisiológica; 2) presença de $X$. campestris pv. vesicatoria e 3) microscopia eletrônica de varredura.

\section{Avaliação da qualidade das sementes}

Para avaliação da qualidade fisiológica e sanitária utilizou-se amostra de 400 sementes por tratamento, distribuídas em 16 repetições de 25 sementes. Utilizou-se o método de crescimento em caixas tipo Gerbox (Silva \& Carmo, 1999), onde, distribuíram-se 25 sementes por Gerbox contendo como substrato três folhas de papel de filtro autoclavadas e umedecidas em 2,5 vezes o peso do papel. As caixas Gerbox foram colocadas em bandejas de dimensões de $0,15 \times 0,60 \times 0,80 \mathrm{~m}$ e, em seguida, cobertas com sacos de plástico transparente, permitindo com isso manter a penetração de luz e o ambiente saturado de umidade. Em seguida, as bandejas foram acondicionadas em câmara de crescimento regulada para $27{ }^{\circ} \mathrm{C}$ e $12 \mathrm{~h}$ de fotoperíodo. Utilizou-se o delineamento inteiramente ao acaso com 16 repetições por tratamento. As observações para constatação de sintomas foram feitas diariamente até o décimo dia. Plântulas com lesões nas folhas primárias e/ou definitivas e no hipocótilo, foram coletadas e anotadas para posterior confirmação da presença bacteriana por meio de teste de exsudação em lâmina, isolamento em meio de cultura DYGS, teste de patogenicidade e crescimento em meio de asparagina. Os dados, expressos em porcentagem de plântulas totais germinadas aos 14 dias, e de plântulas com sintomas de necrose e de plântulas com presença confirmada de $X$. campestris pv. vesicatoria, aos dez dias, foram submetidos à análise de variância e teste de Tukey, ambos a 5\%.

\section{Quantificação de $X$. campestris pv. vesicatoria}

Para avaliação e quantificação de $X$. campestris pv. vesicatoria utilizaram-se ainda dois métodos indiretos. No primeiro, tomou-se uma amostra de $15 \mathrm{~g}$ (cerca 5.000 sementes) para cada um dos quatro tratamentos e procedeu-se a extração pelo método à vácuo (Bashan \& Assouline, 1983). Cada amostra foi colocada em erlenmeyer contendo $30 \mathrm{ml}$ de solução tampão fosfato $0,005 \mathrm{M}, \mathrm{pH} 7,4+0,85 \%$ de $\mathrm{NaCl}$ (Kimura \& Freitas, 1993), seguido de repouso por $1 \mathrm{~h} \mathrm{a} 4{ }^{\circ} \mathrm{C}$. Após este período aplicou-se à mistura dois ciclos consecutivos de vácuo de $680 \mathrm{~mm} \mathrm{Hg}$ por $5 \mathrm{~min}$, seguido de liberação rápida. Posteriormente, as sementes foram peneiradas e o extrato obtido foi submetido à diluição em série 1:10, em solução salina a $0,85 \%$. Seguiu-se o plaqueamento em três meios de cultura: Nutriente Agar (NA) (Fahy \& Hayward, 1983), Nutriente Agar Tween (NAT) (Maringoni, 1993) e Tween A Modificado (TAM) (McGuire et al., 1986). Distribuíram-se alíquotas de 0,1 ml por placa de Petri, com três placas por diluição, totalizando 30 placas para cada combinação tratamento $\mathrm{x}$ meio de cultura. Os extratos e as respectivas diluições foram ainda inoculados em plantas de tomate, variedade Kada, com 30 dias de idade, por meio de infiltração com seringas hipodérmicas. Inocularam-se duas folhas de cinco plantas para cada amostra. As plantas foram acondicionadas em ambiente com temperatura de $26 \pm 2{ }^{\circ} \mathrm{Ce}$ alta umidade relativa (acima de 90\%) e observadas diariamente até a constatação de sintomas. Para confirmação da presença da bactéria foram feitos isolamentos a partir das lesões em meio NA. Os resultados foram expressos com base no crescimento nos respectivos meios e no desenvolvimento de sintomas nas plantas inoculadas, nas diferentes diluições.

\section{Microscopia eletrônica de varredura (MEV)}

Amostras de sementes de tomate, cultivar Santa Clara, inoculadas e tratadas termicamente e apenas inoculadas, tomadas aleatoriamente, foram preparadas para observação ao microscópio eletrônico de varredura (MEV). Sementes inteiras ou sementes seccionadas transversalmente, longitudinalmente e medialmente, foram fixadas em solução contendo glutaraldeído $2,5 \%$ em tampão fosfato $50 \mathrm{mM} \mathrm{pH}$ 7,0 por um período de $24 \mathrm{~h}$. Decorrido este período, as sementes foram lavadas no mesmo tampão (três vezes de 15 min cada), sendo então pós-fixadas em solução aquosa de tetróxido de ósmio a 1\%, seguida de três lavagens em água destilada (três vezes de 10 min cada). Após a fixação, as sementes foram submetidas à desidratação gradual em série acetônica crescente $(15,30,50,70,90,95$ e $100 \%$ acetona em água destilada), permanecendo 15 min em cada solução. Após a desidratação completa, as amostras foram secas pelo método de ponto crítico de secagem, utilizando para tal o aparelho Bal-tec CPD030. Após a secagem, as sementes foram cuidadosamente manipuladas com uma pinça fina e montadas sobre porta amostras de alumínio. As sementes foram aderidas ao porta-amostra por meio de uma fita adesiva condutiva. As amostras foram então metalizadas com ouro ionizado, utilizando um aparelho Bal-tec SCD 050 em atmosfera de argônio, tempo de $80 \mathrm{~s}$ de deposição e corrente de $40 \mathrm{~mA}$. Após a metalização, as amostras foram levadas para o microscópio eletrônico de varredura Zeiss DSEM 962 para observação.

\section{Experimento II}

No segundo ensaio, utilizaram-se sementes comerciais de tomate, cultivar Tropic, e o isolado de X. campestris pv. vesicatoria ENA 4463. Compararam-se três tratamentos: 1) sementes inoculadas a vácuo; 2 ) sementes inoculadas à vácuo e submetidas ao tratamento térmico $70{ }^{\circ} \mathrm{C}$ por $96 \mathrm{~h}$ e 3 ) testemunha, sementes não inoculadas e não tratadas. As sementes foram inoculadas conforme a metodologia descrita anteriormente (Bashan \& Assouline, 1983), porém o isolado foi previamente cultivado, em três ciclos seguidos no meio semi-seletivo NAT. Seguiu-se o mesmo procedimento de secagem, tratamento e armazenamento das sementes até o momento da avaliação da qualidade fisiológica e para a presença de $X$. campestris pv. vesicatoria.

\section{Avaliação da qualidade das sementes}

Para avaliação da qualidade fisiológica utilizou-se a metodologia descrita nas Regras para Análise de Sementes (RAS) (Ministério de Agricultura e Reforma Agrária, 1992). 
Termoterapia via calor seco no tratamento de sementes de tomate...

Utilizaram-se amostras de 400 sementes por tratamento, distribuídas em 16 Gerbox com 25 sementes, sendo cada caixa uma repetição. Como substrato, foram utilizadas três folhas de papel de filtro autoclavadas e umedecidas em 2,5 vezes o peso do papel. Após distribuição das sementes as caixas foram acondicionados em germinador regulado para $8 \mathrm{~h}$ de luz e 16 $\mathrm{h}$ de escuro e temperatura de 30 e $20^{\circ} \mathrm{C}$, respectivamente. As contagens foram feitas aos cinco e 14 dias seguindo critério descrito nas RAS (Ministério da Agricultura e Reforma Agrária, 1992). Os dados foram expressos em porcentagem e submetidos a análise de variância e teste de Tukey a 5\% de probabilidade.

\section{Quantificação de $X$. campestris pv. vesicatoria}

Para quantificação de $X$. campestris pv. vesicatoria tomaram-se amostras de 15.000 sementes por tratamento que foram distribuídas em três repetições de 5.000 sementes, perfazendo um total de nove parcelas, em delineamento inteiramente ao acaso. As amostras foram submetidas ao mesmo processo de extração citado, conforme Bashan \& Assouline (1983). Em seguida, as sementes foram peneiradas e o extrato obtido de cada amostra foi submetido a centrifugação a $14.000 \mathrm{rpm}$ por $30 \mathrm{~min}$, à temperatura de $5{ }^{\circ} \mathrm{C}$. O "pellet" formado foi ressuspendido em $2 \mathrm{ml}$ de solução salina seguido de diluição seriada (série 1:10), também em solução salina, e plaqueamento em meio semi-seletivo NAT.

\section{Avaliação da eficiência do tratamento}

Os dados foram expressos em número de unidade formadoras de colônia por grama de sementes $\left(\mathrm{n}^{\circ} \mathrm{ufc} / \mathrm{g}\right.$ sementes), transformados para $\log \left(\mathrm{n}^{\mathrm{o}} \mathrm{ufc} / \mathrm{g}\right)$ e submetidos a análise de variância e teste de Tukey, ambos a $1 \%$ de probabilidade. Calculou-se, ainda, a eficiência dos tratamentos (T) em porcentagem (E\%), por meio da relação entre a recuperação da bactéria, expressa em ufc/g de sementes, a partir das amostras dos respectivos tratamentos (inoculadas e tratadas (IT), inoculadas e não tratadas (INT) e não inoculadas e não tratadas (NIT)) e a amostra das sementes apenas inoculadas (INT): $\mathrm{E} \%=\left(1-\left(\mathrm{n}^{\circ} \mathrm{ufc} / \mathrm{g} \mathrm{T}\right) /\left(\mathrm{n}^{\circ} \mathrm{ufc} / \mathrm{g} \mathrm{INT}\right)\right)$ $\mathrm{x} 100$.

\section{RESULTADOS E DISCUSSÃO}

No primeiro ensaio, observou-se no tratamento de inoculação a vácuo expressão de sintomas em $81 \%$ das plântulas e recuperação da bactéria em todos os meios e plantas indicadoras inoculadas (Tabela 1). O tratamento térmico foi $100 \%$ eficiente na erradicação de $X$. campestris $p v$. vesicatoria, para todos os métodos de detecção utilizados. Quanto à germinação, os tratamentos não inoculado/ não tratado (NI/NT) e inoculado/ tratado a $70{ }^{\circ} \mathrm{C} / 96$ h (IT) não diferiram entre si, porém foram superiores aos dois demais tratamentos, inoculado/ não tratado (I/NT) e não inoculado/ tratado (NI/T), que por sua vez também não diferirem entre si (Tabela 1). Essas diferenças entre os tratamentos provavelmente estão associadas a diferenças no teor de umidade destas, que não foi determinado, e a um provável efeito da pré-embebição das sementes antes do tratamento térmico. Esta hipótese, no entanto, precisa ser avaliada com estudos mais específicos na área de fisiologia de sementes. $O$ teor de umidade pode ter afetado não só a velocidade da germinação como o desenvolvimento de outros patógenos de sementes, fungos e Erwinia sp., como pode ser constatado pela maior porcentagem de plântulas anormais infetadas no tratamento I/NT (Tabela 1).

Observaram-se diferenças quanto à sensibilidade entre os métodos de detecção por extração seguido de plaqueamento em diferentes meios ou inoculação em planta indicadora. Entre os meios utilizados, o NAT foi o que se mostrou mais sensível, tendo detectado a bactéria até a diluição de $10^{-6}$, seguido de TAM e NA. A maior recuperação da bactéria no meio NAT comparado ao TAM deve-se à menor supressividade do primeiro em relação ao segundo, $22 \%$ e $44 \%$, respectivamente, em relação ao meio NA (Silva, 1999). No presente ensaio, no entanto, observou-se no meio NA, intenso crescimento de fungos e bactérias que inibiram o crescimento de $X$. campestris pv. vesicatoria e dificultaram a identificação das colônias e o reisolamento do patógeno em estudo. O método de inoculação em planta indicadora mostrou-se, nas condições utilizadas, pouco sensível, com recuperação do patógeno somente até a diluição de $10^{-3}$, confirmando os resultados de Valarini (1995).

No segundo ensaio, quando se fez uma análise mais detalhada da qualidade fisiológica das sementes submetidas aos respectivos tratamentos, pode-se observar que o tratamento térmico reduziu o vigor das sementes, avaliado pela germinação aos cinco dias, mas não afetou a germinação final, avaliada aos 14 dias (Tabela 3). Apesar de não quantificado no presente ensaio, observou-se um alto crescimento de fungos e bactérias nas amostras não tratadas, que muitas vezes confundiram-se com os sintomas causados por $X$. campestris pv. vesicatoria. A redução do vigor nas amostras tratadas foi compensada pela melhor desenvolvimento das plântulas devido a ausência destes patógenos, tanto a fitobactéria em estudo, como fungos de armazenamento, normalmente associados à redução da qualidade fisiológica de sementes (Tabelas 1 e 3). Ainda, a diferença entre o primeiro e o segundo ensaio quanto à porcentagem de plântulas anormais infetadas, em sua maioria com sintomas de necrose, deve-se ao nível de detalhamento usado nas respectivas avaliações. No primeiro, examinou-se cada plântula ao microscópio estereoscópico além de se ter efetuado teste de exsudação em lâmina e isolamento para cada alteração observada na estrutura das folhas cotiledonares e hipocótilo (anasarcas, necrose ou amarelecimento). No segundo efetuou-se a observação a olho nu, seguindo a rotina de um teste de germinação, sem levar em conta os minúsculos sintomas causados por $X$. campestris pv. vesicatoria, muitas vezes só perceptíveis sob observação minuciosa ao microscópio estereoscópico. É importante ainda salientar que muitas vezes os sintomas causados por $X$. campestris pv. vesicatoria podem, neste tipo de teste, ser confundidos com aqueles causados por 
TABELA 1 - Porcentagem de germinação, de plântulas com sintomas de necrose e anasarca no hipocótilo e folhas cotiledonares e de plântulas infetadas por Xanthomonas campestris pv. vesicatoria obtidas a partir de amostras de sementes de tomate (Lycopersicon esculentum), cv. Santa Clara, submetidas a quatro tratamentos

\begin{tabular}{|c|c|c|c|c|}
\hline \multirow{2}{*}{ Tratamento } & \multirow{2}{*}{ Descrição } & \multirow{2}{*}{ Germinação \% } & \multicolumn{2}{|c|}{ Plântulas (\%) } \\
\hline & & & Anormais infetadas & X. campestris pv. vesicatoria \\
\hline $\mathrm{NI} / \mathrm{NT}$ & Testemunha (não inoculadas/não tratadas) & $78,00 \mathrm{a}$ & $38,00 \quad \mathrm{~b}$ & $0,0 \quad \mathrm{~b}$ \\
\hline $\mathrm{I} / \mathrm{T}$ & Inoculadas e tratadas $\left(70^{\circ} \mathrm{C} / 96 \mathrm{~h}\right)$ & $75,25 \mathrm{a}$ & 0,25 & $0,0 \mathrm{~b}$ \\
\hline I/NT & Inoculadas e não tratadas & $71,00 \mathrm{~b}$ & 85,00 a & $81,25 \mathrm{a}$ \\
\hline \multirow[t]{2}{*}{$\mathrm{NI} / \mathrm{T}$} & Não inoculadas e tratadas $\left(70^{\circ} \mathrm{C} / 96 \mathrm{~h}\right)$ & $69,00 \mathrm{~b}$ & $11,00 \quad \mathrm{c}$ & $0,0 \mathrm{~b}$ \\
\hline & $\mathrm{CV}(\%)$ & 2,11 & 6,81 & 13,58 \\
\hline
\end{tabular}

${ }^{(1)}$ Médias seguidas pela mesma letra, na coluna, não diferem estatisticamente pelo teste de Tukey a 5\%; média de quatro repetições de 100 sementes.

TABELA 2 - Eficiência do tratamento térmico a $70^{\circ} \mathrm{C} / 96 \mathrm{~h}$, via calor seco, na erradicação de Xanthomonas campestris pv. vesicatoria de sementes de tomate (Lycopersicon esculentum), cv. Tropic

\begin{tabular}{|c|c|c|}
\hline Tratamento $(\mathbf{T})$ & $\begin{array}{c}\text { Número de u.f.c./g de } \\
\text { sementes }\end{array}$ & Eficiência $(\%)^{2}$ \\
\hline Inoculadas e não tratadas (INT) & $1,68 \times 10^{6} \mathrm{a}$ & 0 \\
\hline Inoculadas e tratadas $\left(70^{\circ} \mathrm{C} / 96 \mathrm{~h}\right)(\mathrm{IT})$ & $5,58 \times 10^{2} b$ & 99,96 \\
\hline Testemunha (não inoculadas/não tratadas) (NIT) & 0 & 100 \\
\hline $\mathrm{CV} \%$ & 3,49 & \\
\hline
\end{tabular}

TABELA 3 - Efeito da inoculação com Xanthomonas campestris pv. vesicatoria e do tratamento térmico a seco $\left(70{ }^{\circ} \mathrm{C} /\right.$ $96 \mathrm{~h}$ ) sobre a qualidade fisiológica de sementes de tomate (Lycopersicon esculentum), cv. Tropic

\begin{tabular}{|c|c|c|c|c|c|c|}
\hline \multirow{2}{*}{ Tratamento } & \multicolumn{2}{|c|}{ Plântulas normais (\%)* } & \multicolumn{2}{|c|}{ Sementes (\%) } & \multicolumn{2}{|c|}{ Plântulas anormais (\%) } \\
\hline & 5 dias & 14 dias & Deterioradas & Não germinadas & Deformadas & Infetadas \\
\hline Inoculadas e não tratadas & $81,25 \mathrm{a}$ & $91,00 \mathrm{a}$ & $2,50 \mathrm{a}$ & $3,75 \mathrm{a}$ & $0,50 \mathrm{a}$ & $2,00 \mathrm{a}$ \\
\hline Testemunha (não inoculadas/não tratadas) & $81,25 \mathrm{a}$ & $89,00 \mathrm{a}$ & $3,00 \mathrm{a}$ & $7,25 \mathrm{a}$ & $0,00 \mathrm{a}$ & $0,75 \mathrm{a}$ \\
\hline Inoculadas e tratadas $\left(70^{\circ} \mathrm{C} / 96 \mathrm{~h}\right)$ & $54,25 \mathrm{~b}$ & 89,75 a & $1,50 \mathrm{a}$ & $6,75 \mathrm{a}$ & $0,50 \mathrm{a}$ & $1,50 \mathrm{a}$ \\
\hline $\mathrm{CV}(\%)$ & 11,53 & 3,7 & 3,37 & 3,7 & 1,1 & 3,3 \\
\hline
\end{tabular}

*Médias seguidas pela mesma letra, não diferem estatisticamente pelo teste de TuKey a 5\% de significância; média de 16 repetições de 25 sementes.

outros organismos secundários, como Erwinia spp. e com a própria cicatriz deixada pelo tegumento na extremidade das folhas cotiledonares. Tanto que, no segundo ensaio, quando foram feitas avaliações seguindo os padrões de rotina de análise de sementes, não houve diferença entre os tratamentos quanto à porcentagem de plântulas anormais devido a infecções. Ainda, a fitobactéria não interferiu na qualidade fisiológica das sementes (Tabela 3).

Os efeitos da termoterapia sobre a estrutura das sementes e da bactéria, foram avaliados em MEV em amostras de sementes (cv. Santa Clara) inoculadas a vácuo com $X$. campestris pv. vesicatoria e submetidas ao tratamento térmico (Figura 1B,C,D) ou não (Figura 1A). Os efeitos mais marcantes da ação do calor sobre a estrutura da superfície da semente foram percebidos na região dos tricomas. Estes incluem remoção e quebra de tricomas, que em muitas observações apresentavam-se depositados aleatoriamente entre si sobre a superfície do tegumento da semente (Figura
1B,C). Outro aspecto bastante evidente resultou da aparente fusão de tricomas, formando placas (Figura 1D) quando estes se apresentavam paralelos entre si ou mesmo formando uma trama de tricomas sobre a superfície (Figura 1C). Associada à ação do tratamento termoterápico sobre a estrutura da semente, foi observada a ação direta do calor sobre a estrutura da bactéria (Figura 1E). Bactérias aderidas à superfície de tricomas fusionados apresentavam perda de integridade celular e sinais de dessecação, como aqueles observados pela presença de resíduos de material extracelular de bactérias removidas da superfície da semente e pela alteração da forma da bactéria (Figura 1E). Entretanto, a ação direta do tratamento térmico sobre a morfologia da bactéria não foi um fenômeno generalizado. Muitas bactérias aderidas ao tegumento não apresentavam qualquer alteração morfológica aparente, o que não significaria necessariamente dizer que estas estejam viáveis. O presente resultado referiu-se à contaminação superficial das sementes devido à inoculação 


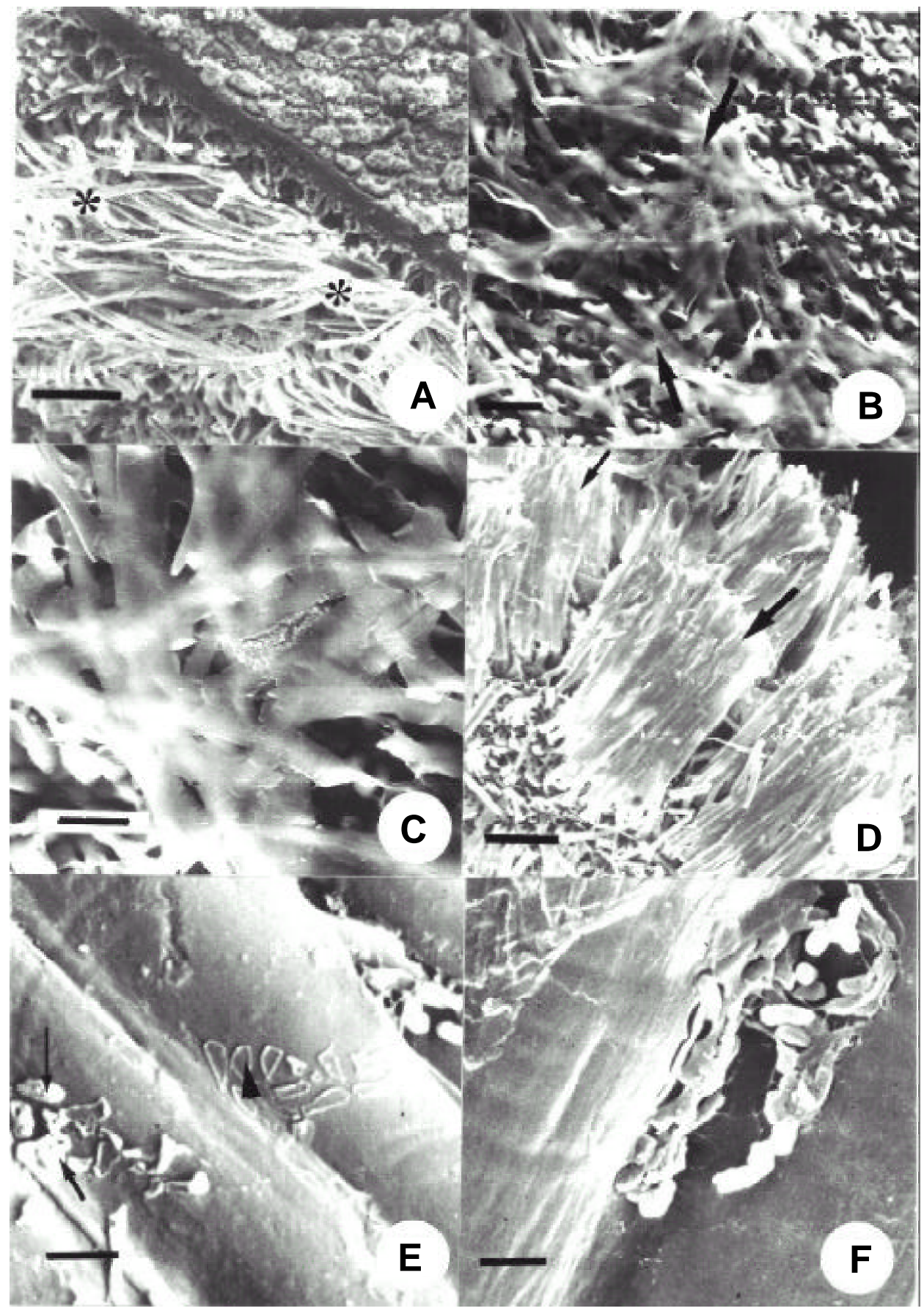

FIG. 1 - Fotomicrografias eletrônicas de varredura (FMEV) de sementes de tomate (Lycopersicon esculentum), cv. Santa Clara, inoculadas a vácuo com Xanthomonas campestris pv. vesicatoria (A) e inoculadas e tratadas a 70 ${ }^{\circ} \mathrm{C}$ por 96 h. (B-F) evidenciando: A) seção transversal, na porção mediana, com grande número de tricomas íntegros e individualizados (asteriscos) - Barra $=100 \mu \mathrm{m} ; \mathrm{B}$ ) visão geral da superfície do tegumento evidenciando um grande número de tricomas quebrados e parcialmente sobrepostos aleatoriamente entre si (setas). Barra = $50 \mu \mathrm{m}$; C) detalhe da foto $B$ evidenciando os tricomas quebrados e dispostos aleatoriamente entre si, com alteração na superfície do tricoma. Barra $=20 \mu \mathrm{m}$; D) formação de placas na zona rica em tricomas (setas) como resultado da fusão de tricomas individuais, decorrentes do tratamento térmico. Barra $=100 \mu \mathrm{m} ; \mathbf{E}$ ) efeito da exposição ao calor na morfologia das bactérias, causando dessecação e perda de integridade celular (setas), bem como evidenciando a interface de contato entre a bactéria removida da superfície e o tegumento (cabeça de seta). Barra $=2 \mu \mathrm{m} ; \mathrm{F}$ ) microcolônia de bactérias colonizando cavidade formada pela fusão de dois tricomas, envolvidas por um material de aparência mucilaginosa. Algumas bactérias, mesmo após a ação do calor, apresentam estrutura aparentemente íntegra. Barra $=2 \mu \mathrm{m}$. 
artificial. Não existem na literatura estudos específicos sobre a localização de $X$. campestris pv. vesicatoria em sementes de tomate e os trabalhos, em geral, referem-se apenas à transmissão externa (Maringoni \& Kurozawa, 1994; Silva, 1999).

Quanto à eficiência do tratamento térmico na erradicação da bactéria, os resultados obtidos no segundo ensaio discordam daqueles observados no primeiro, porém confirmam a indicação das observações ao MEV sobre a presença de células intactas (Figura 1F). Nesse verificou-se uma eficiência de $99,966 \%$ (Tabela 2) contra $100 \%$ na erradicação de X. campestris pv. vesicatoria nas sementes no primeiro ensaio. Esta variação pode ser atribuída ao uso de amostra maior no segundo ensaio, 15.000 sementes, e ao précultivo do patógeno no meio seletivo NAT, permitindo a seleção de estirpes com maior taxa de crescimento no meio. Amostras maiores aumentam a probabilidade de recuperação de células viáveis da bactéria e a sensibilidade na avaliação da eficiência dos tratamentos. Para fins de certificação, no entanto, deverão ser feitos trabalhos específicos que estabeleçam o tamanho e o número ideal de amostras. O uso de isolado pré-cultivado no meio seletivo foi feito com o objetivo de aumentar a taxa de recuperação da bactéria uma vez que existe grande variação na população desta quanto à taxa de crescimento em meios semi-seletivos. O meio NAT promove, em média, redução de $22 \%$ no crescimento da bactéria em estudo (Silva, 1999). Esta diferença entre os ensaios é mais clara quando se compara a quantidade de bactéria recuperada em ambos os ensaios, bem maior no segundo ensaio que no primeiro. Estes resultados confirmam os de Azevedo et al. (1991) que relatam eficiência de 99,99\% na erradicação de $X$. campestris pv. vesicatoria em sementes de pimentão via calor seco a $70^{\circ} \mathrm{C}$ por $96 \mathrm{~h}$. Estes resultados, no entanto, precisam ser avaliados sob o ponto de vista epidemiológico. Sabe-se que para pimentão, uma semente infetada em 10.000 pode resultar em infecção generalizada das mudas (Carmo et al., 1996). Não existe porém estudo semelhante para tomate nem informação quantitativa sobre o número mínimo de células bacterianas necessárias para desencadear o processo de infecção em sementes e transmissão às plântulas. Os resultados sugerem, no entanto, que a termoterapia é uma forma eficiente de reduzir a população bacteriana em sementes de tomate e poderá vir a ser uma ferramenta complementar importante no manejo da doença.

Após uma análise geral dos diferentes métodos de detecção utilizados, constatou-se que o plaqueamento no meio semi-seletivo NAT é superior aos demais e que o método de inoculação em planta indicadora é menos sensível, além de apresentar maiores dificuldades operacionais, apesar de confirmar, diretamente, a virulência das células bacterianas associadas às sementes. O método de crescimento em Gerbox, por sua vez, apresenta dificuldades associadas à interpretação dos resultados e a baixa sensibilidade devido ao pequeno tamanho da amostra.

Finalmente, os resultados do presente trabalho indicam boas perspectivas da utilização do tratamento térmico no controle de $X$. campestris pv. vesicatoria em sementes de tomateiro, não só pela eficiência do método como também pela simplicidade de aplicação e por não comprometer a qualidade fisiológica das sementes, apesar de provocar alterações na sua estrutura externa. Além deste aspecto, o tratamento apresenta amplo espectro, incluindo fungos de armazenamento, porém, o potencial de armazenamento das sementes tratadas necessita ser avaliado. Os resultados indicam, ainda, a importância de se trabalhar com amostras maiores e com métodos que otimizem o crescimento bacteriano a fim de se aumentar a sensibilidade na avaliação da eficiência dos tratamentos. E, embora o tratamento térmico tenha se mostrado eficiente para o controle de $X$. campestris pv. vesicatoria em sementes de tomate, a eficiência não é de $100 \%$, o que aponta a necessidade de estudos epidemiológicos, em condições de viveiro. Diferentes combinações de temperatura e tempo de exposição podem ainda ser confrontados, principalmente associados com tratamentos prévios às sementes visando reduzir os danos às mesmas. Esta hipótese é substanciada pela melhoria do desempenho das sementes tratadas termicamente após serem submetidas à hidratação via inoculação, comparada às sementes tratadas sem nenhum tratamento prévio (Tabela 1) e por trabalhos na área de tecnologia de sementes envolvendo técnicas de précondicionamento, onde se destacam as de condicionamento osmótico que consiste na pré-embebição das sementes em solução de potencial osmótico conhecido (Eira \& Marcos Filho, 1990).

\section{AGRADECIMENTOS}

Ao CNPq e a FAPERJ pela concessão das bolsas de Mestrado e de Iniciação Científica do primeiro e último autores, respectivamente. Ao DenF-Área de Fitopatologia, pela estrutura e fornecimento de material. À valiosa contribuição do técnico em microscopia do LBCT/UENF, Sr. Noil Gomes de Freitas.

\section{REFERÊNCIAS BIBLIOGRÁFICAS}

AGUIAR, L.A. de, KIMURA, O., CASTILHO, A.M.C., CASTILHO, K.S.C., RIBEIRO, R.L.D., AKIBA, F. \& CARMO, M.G.F. Resistência ao cobre em isolados nacionais de Xanthomonas campestris pv. vesicatoria. Agronomia 34:78-82. 2000.

AZEVEDO, J.M.N., KIMURA, O., RIBEIRO, R.L.D. \& AKIBA, F. Tratamento térmico de sementes de pimentão objetivando a erradicação de Xanthomonas campestris pv. vesicatoria. Fitopatologia Brasileira 16:44. 1991. (Resumo).

BASHAN, Y. \& ASSOULINE, I. Complementary bacterial enrichment techniques for the detection of Pseudomonas syringae pv. tomato and Xanthomonas campestris pv. vesicatoria in infested tomato and pepper seeds. Phytoparasitica 11:187-193. 1983.

CARMO, M.G.F., KIMURA, O., MAFFIA, L.A. \& CARVALHO, A.O.C. Progresso da pústula bacteriana do pimentão, causada por Xanthomonas campestris pv. vesicatoria em condições de viveiro. Fitopatologia Brasileira 20:66-70. 1996. 
Termoterapia via calor seco no tratamento de sementes de tomate...

EIRA, M.T.S. \& MARCOS FILHO, J. Condicionamento osmótico de sementes de alface. II-Desempenho sob estresses hídrico, salino e térmico. Revista Brasileira de Sementes 12:28-45. 1990.

FAHY, P.C. \& HAYWARD, A.C. Media and methods for isolation and diagnostic test. In: Fahy, P.C. \& Persley, G.J. (Ed.) Plant bacterial diseases: a diagnostic guide. Sydney. Academic Press. 1983. pp. 337-338.

JONES, J.B., WOLTZ, S.S., JONES, J.P. \& PORTIER, K.L. Population dynamics of Xanthomonas campestris $p v$. vesicatoria on tomato leaflets treated with copper bactericides. Phytopathology 81:714-719. 1991.

GRONDEAU, C. \& SAMSON, R. A review of thermotherapy to free plant materials from pathogens, especially seeds from bacteria. Critical Reviews in Plant Sciences 13:57-75. 1994.

IBGE. http://www.ibge.net/home/estatistica/economia/pam/ tabela1pam.shtm, 07/2002.

KIMURA, O. \& FREITAS, R. DA S. Influência da solução extratora na detecção de Xanthomonas campestris pv. vesicatoria em sementes de tomate. Fitopatologia Brasileira 18:277. 1993 (Resumo).

KIMURA, O. Controle de fitobactérias em hortaliças através do tratamento térmico de sementes. Fitopatologia Brasileira 16:8. 1991 (Resumo).

LOPES, C.A. \& SANTOS, J.R.M. Doenças do tomateiro. Brasília. EMBRAPA-CNPH. 1994.

MARCO, G.M. \& STALL, R.E. Control of bacterial spot of pepper initiated by strains of Xanthomonas campestris pv. vesicatoria that differ in sensitivity to copper. Plant Disease 67:779-781. 1983.

MARINGONI, A.C. Detecção de Xanthomonas campestris pv. phaseoli (Smith) Dye em sementes de feijoeiro e consequências epidemiológicas. (Tese de Doutorado). Piracicaba. Escola Superior de Agricultura Luiz de Queiroz. 1993.

MARINGONI, A.C. \& KUROZAWA, C. Erradicação de Xanthomonas campestris pv. vesicatoria em sementes de tomateiro. Revista Brasileira de Sementes 16:191-194. 1994.
McGUIRE, R.G., JONES, J.B. \& SASSER, M. Tween medium for semiselective isolation of Xanthomonas campestris pv. vesicatoria from soil and plant material. Plant Disease 70:887891. 1986.

MENTEN, J.O.M. Patógenos em Sementes, Detecção, Danos e Controle Químico. São Paulo. Ciba Agro. 1995.

MINISTÉRIO DA AGRICULTURA E DA REFORMA AGRÁRIA. Regras para Análise de Sementes. Brasília, SNDA / DNDV / CLAV, 1992.

ROBBS, C.F. Doenças causadas por bactéria. Informe Agropecuário 11: 45-50. 1985

RODRIGUES NETO, J., MALAVOLTA J.R., V.A. \& VICTOR, O. Meio simples para o isolamento e cultivo de Xanthomonas campestris pv. citri tipo B. Summa Phytopathologica 12:16. 1986 (Resumo)

ROMEIRO R.S. Fundamentos de Bacteriologia de Plantas. Viçosa. Universidade Federal de Viçosa. Imp. Univ. 1988.

SCHAAD, N.W. Bacteria: Inoculum thresholds of seedborne pathogens. Phytopathology 78:872-875. 1988.

SILVA, A.M.S. Detecção, erradicação e localização de Xanthomonas campestris pv. vesicatoria em sementes de tomate (Lycopersicon esculentum). (Tese de Mestrado). Seropédica. Universidade Federal Rural do Rio de Janeiro. 1999.

SILVA, A.M.S. \& CARMO, M.G.F. Detecção de Xanthomonas vesicatoria em sementes de tomate pelo teste de crescimento. In: XI Congresso Brasileiro de Sementes, Foz do Iguaçu, PR. Informativo ABRATES. 1999. v.9. p.108.

STALL, R.E. \& THAYER, P.L. Streptomycin resistance of the bacterial spot pathogen and control with streptomycin. Plant Disease Reporter 46: 389-9. 1962.

VALARINI, P. Métodos de detecção de Clavibacter michiganensis subsp. michiganensis e Xanthomonas vesicatoria em sementes de tomate. Revista Brasileira de Sementes 17:179186. 1995.

ZAMBOLIM, L., VALE, F.X.R. \& COSTA, H. Controle integrado de doenças de hortaliças. Viçosa, Suprema Gráfica e Editora Ltda. 1997. 